\title{
Food Protein-Induced Non-Immunoglobulin E-Mediated Allergic Colitis in Infants and Older Children: What Cytokines Are Involved?
}

\author{
Ahmet Ozen $^{\mathrm{a}}$ Enver Mahir Gulcan ${ }^{\mathrm{b}}$ Hulya Ercan Saricoban ${ }^{\mathrm{a}}$ Ferda Ozkan $^{\mathrm{c}}$ \\ Reha Cengizlier ${ }^{a}$
}

Divisions of a Pediatric Allergy, ${ }^{\mathrm{b}}$ Pediatric Gastroenterology, Hepatology and Nutrition and ${ }^{\mathrm{c} P a t h o l o g y,}$

Faculty of Medicine, Yeditepe University, Istanbul, Turkey

\section{Key Words \\ CD86 · Food protein-induced allergic proctocolitis . \\ Transforming growth factor- $\beta$ - Transforming growth \\ factor- $\beta$ receptor- 1 . Tumor necrosis factor- $\alpha$. \\ Mucosal tolerance $\cdot$ Cow's milk allergy}

\begin{abstract}
Background: Food protein-induced allergic proctocolitis (FPIAP) is mostly a non-immunoglobulin E-mediated disease where a T-cell-mediated reaction to cow's milk protein has been suggested. We determined the expression of transforming growth factor (TGF)- $\beta$, TGF- $\beta$ receptor- 1 , tumor necrosis factor (TNF)- $a, C D 86$, and CD23 on the colon mucosa to investigate their roles in the pathogenesis of the two subtypes of FPIAP, i.e. infantile FPIAP and FPIAP in older children. Methods: Group 1 comprised children with infantile FPIAP (age $<6$ months, $\mathrm{n}=21$ ), group 2 referred to FPIAP in older children (age $>1.5$ years, $n=7$ ), and group 3 included children with juvenile hyperplastic polyps $(n=22)$. Immunohistochemical staining of colonic biopsy specimens was performed. Results: The expression of TNF-a was significantly higher in groups 1 and 2 compared to group 3 . Group 2 patients had a significantly lower TGF- $\beta$ expression compared to the other groups. The expression of CD86 was higher in
\end{abstract}

group 1 than in group $3(p=0.012)$. Eosinophil counts per high-power field in the lamina propria were significantly correlated with CD86 expression $(p=0.026, r=0.388)$. Conclusion: Our results suggest that TNF- $a$ is implicated in the pathogenesis of both types of FPIAP. The decreased activity of TGF- $\beta$ receptor- 1 accompanied by the increased expression of CD86 in infants and the decreased activity of TGF- $\beta$ in older children appear to play a role in the development of FPIAP.

(c) 2015 S. Karger AG, Basel

\section{Introduction}

Food protein-induced allergic proctocolitis (FPIAP) of infancy is the most common cause of bloody stools in the first year of life, and rectal and colonic biopsies show significant eosinophilic infiltration of the lamina propria as its most prominent feature [1-4]. Unlike other eosinophilic gastrointestinal disorders (EGID), eosinophilic colitis is usually a non-immunoglobulin $\mathrm{E}$ (IgE)-associated disease where a T lymphocyte-mediated process has been suggested as the underlying mechanism [5]. Recently, a microarray analysis of mucosal biopsy specimens demonstrated that the expression of CCL11 and CXCL13,

\section{KARGER 125}

(c) 2015 S. Karger AG, Base

$1018-2438 / 15 / 1681-0061 \$ 39.50 / 0$

E-Mail karger@karger.com

www.karger.com/iaa
Correspondence to: Dr. Ahmet Ozen

Division of Pediatric Allergy, Faculty of Medicine, Yeditepe University

Akfirat Beldesi, 33. sok. No: 2, Tuzla

Istanbul (Turkey)

E-Mail ahmetozen_md@yahoo.com 
but not TH1-, TH2-, or TH17-related molecules, was significantly enhanced in these patients [6]. Although the condition is largely considered a disease of small infants, a recent report described FPIAP also in older children (age 2-14 years), with features remarkably similar to those observed in infancy [7]. Of note, an adult form of eosinophilic colitis, which is not related to food allergy and tends to have a less favorable prognosis, has also been described in rare individuals [8].

Infantile FPIAP occurs in both breast- and formulafed infants. Cow's milk is the most frequently implicated food, though there have been reports involving soy, egg, and wheat [7-9]. Exclusion of the offending protein from the infant's formula or from the lactating mother's diet is followed by prompt clinical remission, with resolution of gross rectal bleeding within 72-96 h and recurrence of symptoms within $72 \mathrm{~h}$ following rechallenge [9]. Typically, patients do not display evidence of IgE sensitization. It has been reported that about $0.5-2.5 \%$ of newborn infants experience hypersensitivity reactions to cow's milk in the first year of life, and that non-IgE-mediated reactions account for about $40 \%$ of milk allergic reactions [10-13].

Food antigen sensitization plays a key role in the development of eosinophilic diseases. Like other allergic gastrointestinal diseases, EGID may result from a loss of oral tolerance or failure to induce tolerance [14]. Previous studies have demonstrated that different cells of the immune system participate in oral tolerance induction, with regulatory $\mathrm{T}$ cells being the most important [14]. The findings of a study on children with multiple food allergies suggested that the dominant immunological abnormality in the small bowel is failure to establish normal numbers of transforming growth factor (TGF)- $\beta$ producing regulatory cells [15]. Similarly, a reduction of both TGF- $\beta$ and its type 1 receptor was demonstrated in the mucosa of infants with food protein-induced enterocolitis [16]. It was suggested that failure to generate Th3 cells, as a result of insufficient stimulation of an innate immune response by commensal intestinal microbes, may be a factor contributing to an impaired development of oral tolerance [17]. The exact pathogenetic mechanisms underlying FPIAP, however, have not been established so far.

Previous reports have identified the critical role of CD28/CTLA-4-CD80/CD86 signaling in the development of allergic responses to peanut, where CD86 interaction is most important in inducing peanut extract-specific IgE responses [17]. Meanwhile, the FceRII/CD23 molecule expressed on the surface of intestinal epithelial cells plays a role in the rapid internalization and transcytosis of IgE-allergen complexes [18]. In this study, we determined the expression of tumor necrosis factor (TNF)- $\alpha$, TGF- $\beta_{1}$, TGF- $\beta$ receptor- 1, CD 86 , and CD 23 in colon biopsies of infants and older children who had been diagnosed with FPIAP. We investigated the expression of those molecules in infants ( $<6$ months) and older children ( $>1.5$ years) with FPIAP and compared the findings with those of hyperplastic polyps.

\section{Methods}

\section{Patients}

The Pediatric Gastroenterology, Hepatology and Nutrition Unit of Yeditepe University Hospital is a referral center for pediatric gastrointestinal disorders. The patients in this study were selected among children referred to our unit for evaluation of rectal bleeding between 2007 and 2010. We included those children with a histological diagnosis of eosinophilic colitis at the initial endoscopic examination and children with juvenile hyperplastic polyps to serve as controls.

In all patients, multiple biopsies were obtained from the descending colon, the sigmoid colon, and/or the rectum under direct vision. At the time of the endoscopy, the children were not receiving any medications that could alter the biopsy results. Eosinophil counts were expressed as average eosinophil counts per high-power field (HPF) in the lamina propria at those sites.

This study was approved by the Yeditepe University Ethics Committee. Written consent was obtained from the parents of all participants. Exclusion criteria included: (i) patients with a primary diagnosis of inflammatory bowel disease at the initial assessment based on a clinical examination, colonoscopy and colonic histology, and other appropriate investigations of stools and serum; (ii) histopathologic findings consistent with other gastrointestinal diseases with or without accompanying eosinophilic infiltration; (iii) identification of an infectious etiology through routine serologic or other microbiologic tests including stool culture for Salmonella enteridis, Shigella dysanteriae, and Campylobacter jejuni, stool antigen tests for rotavirus, adenovirus, norovirus, Entamoeba histolytica, Giardia intestinalis, Cryptosporidium, and Clostridium difficile, and stool examination for ova and parasites, and (iv) systemic diseases associated with eosinophilia.

To investigate the differential features of FPIAP of infancy and that of older children, we included children of 2 age groups: $\leq 6$ months and $>1.5$ years. Unlike the infantile group (group $1, \mathrm{n}=$ 21 ), in which the children had a primary failure to actively tolerate the food antigen (with the exception of small amounts received through maternal milk), the older group (group 2, $\mathrm{n}=7$ ) became reactive following a previous period of unproblematic consumption of the offending food. Group 3 patients $(n=22)$ included children with rectal bleeding who were found to have hyperplastic polyps.

For the purpose of our study, we aimed to keep the study groups uniform in terms of their reactivity to the offending food allergen, which in our case was cow's milk protein. As a brief description of the infantile FPIAP cases followed in our unit, there were a total of 39 infants with FPIAP, 2 of whom were not responsive to a cow's
62

Int Arch Allergy Immunol 2015;168:61-68 DOI: $10.1159 / 000441471$
Ozen/Gulcan/Ercan Saricoban/Ozkan/ Cengizlier 
milk-free diet but did respond favorably to the elimination of egg protein. In total, 5 patients were started on elementary formula with a favorable response; the mothers of 2 of them did not adhere to the diet, and 3 had been a fed cow's milk-based formula when they developed their symptoms. During the observation period, none of the infants required a rebiopsy. In total, the gut biopsy samples of 21 consecutive infants with cow's milk allergy were analyzed in this study and comprised group 1. As for FPIAP of older children, we reviewed the medical files of a total of 14 patients with rectal bleeding and a histological diagnosis of eosinophilic colitis at the initial endoscopic examination for eligibility for this study. Among those 14 patients, 7 did not respond to the oligoantigenic diet and therefore were not included in the current study. The remaining 7 patients fulfilled the inclusion criteria as described below and comprised group 2.

Infantile FPIAP (Group 1). The differential diagnosis of FPIAP in an infant with increased numbers of eosinophils in the lamina propria is relatively straightforward after exclusion of anal fissures and enteric infections, which usually obviates the need for food challenges after an elimination diet [19-21]. In our study, the diagnosis of FPIAP was made when the following 3 criteria were satisfied in the presence of consistent endoscopic and histological findings [21]: (i) small and bright red-colored rectal bleeding with or without mucus in a healthy neonate or infant (age $\leq 6$ months), (ii) no other cause of rectal bleeding (anal fissure, polyp, bleeding diathesis, infection, necrotizing enterocolitis, pseudomembranous colitis, or any other surgical abdominal condition) or systemic symptoms, and (iii) disappearance of rectal blood after elimination of the offending food protein from the infant's or the lactating mother's diet. The elimination diet was continued for at least 6 months, until a cure challenge was carried out to test whether the infants had developed immunological tolerance.

FPIAP of Older Children (Group 2). Like in infantile FPIAP, this group of children presented with rectal bleeding as the major clinical manifestation. None of these patients had signs or symptoms suggestive of inflammatory bowel disease. Biochemical investigations including erythrocyte sedimentation rate, C-reactive protein, anti-Saccharomyces cerevisiae antibodies, and perinuclear antineutrophil cytoplasmic antibodies, as well as serologic and microbiologic tests for bacterial or parasitic pathogens, were all negative. All patients were initially prescribed an oligoantigenic diet with exclusion of cow's milk, eggs, and wheat, which led to the disappearance of symptoms. The major symptom after the reintroduction of milk was rectal bleeding, with or without accompanying diarrhea with mucus. Typically symptoms came within $72 \mathrm{~h}$ of the challenge. After a period of 1 month of complete remission, an open food challenge was performed with the introduction of wheat, eggs, and cow's milk, all 1 month apart, respectively. All children in this group had a positive response to the challenge with cow's milk. The mean duration of follow-up was $10.9 \pm 6.6$ months. One patient had a high total IgE level, was positive to cow's milkspecific IgE, and accompanying atopic dermatitis. Two patients had some other allergic manifestations, i.e. one had nonatopic asthma and the other had recurrent acute urticaria with no sensitization to food antigens or aeroallergens. Rectal bleeding accompanied diarrhea in 1 patient, abdominal pain in 2 , and mucus in 2.

\section{Immunohistochemical Study}

The specimens were examined in a blinded manner by a pathologist experienced in the field of gastrointestinal pathology
Table 1. Immunohistochemical staining scores

\begin{tabular}{llll}
\hline & Group 1 & Group 2 & Group 3 \\
\hline TNF- $^{\text {a }}$ & $1.25(0-3)$ & $1(0-2)$ & $0(0-1)$ \\
TGF- $_{1}{ }^{\text {b }}$ & $1.75(0-3)$ & $0.5(0-1)$ & $1(0-2.5)$ \\
TGF- $\beta_{\text {receptor- }}{ }^{\mathrm{c}}$ & $1(0-3)$ & $2(0.5-2)$ & $2(0-3)$ \\
CD86 $^{\mathrm{d}}$ & $0.5(0-2)$ & $0.5(0-1)$ & $0(0-0.5)$ \\
CD23 & $0(0-0.5)$ & 0 & $0(0-2)$ \\
\hline
\end{tabular}

Values are presented as medians (range). ${ }^{a}$ Groups 1 and 3: $\mathrm{p}<$ 0.0001 , groups 2 and $3: p=0.007 .{ }^{b}$ Groups 1 and $2: p=0.013$, groups 2 and 3: $\mathrm{p}=0.015 .{ }^{\mathrm{c}}$ Groups 1 and $3: \mathrm{p}=0.049 .{ }^{\mathrm{d}}$ Groups 1 and 3: $\mathrm{p}=0.012$.

(F.O.) who was unaware of the clinical and endoscopic findings, and an independent review was also performed. Immunohistochemical studies were performed using the following monoclonal antibodies: TNF- $\alpha$ antibody (GeneTex International Corporation, USA), mouse monoclonal antibody to TGF- $\beta$ (GeneTex), Pierce anti-TGF- $\beta$ receptor I polyclonal antibody (Thermo Scientific Pierce Antibodies), rabbit monoclonal antibody to CD86 (GeneTex), and CD23 antibody (GeneTex). Negative control studies were performed concurrently in the absence of the primary antibody. Positive control studies were also performed simultaneously in parts of a human colon tissue section. Brown staining in cytoplasm was considered positive, and no staining was considered negative.

\section{Quantification of Immunostains}

We assessed the expression of TNF- $\alpha$, TGF- $\beta_{1}$, TGF- $\beta$ receptor-1, CD23, and CD86 on intestinal epithelial cells and mononuclear cells in the lamina propria in a semiquantitative manner, as described previously [18]. Scores were expressed on a scale of $0-3$ in increments of 0.5 according to the extent and intensity of the staining. The extent of the staining was assessed as the number of stained cells per 100 epithelial or mononuclear cells and graded as follows: $0,0 \% ; 1,<25 \% ; 2,25-50 \%$, and $3,>50 \%$. The intensity of the staining was graded as follows: 0 , none; 1 , weak; 2 , moderate, and 3 , strong. The overall staining score was graded as: 0 : intensity $=$ none, extent $=0 \% ; 1$ : intensity $=$ mild, extent $<25 \%$; 2 intensity $=$ moderate, extent $=25-50 \%$, and 3 : intensity $=$ severe, extent $>50 \%$.

\section{Results}

We had the following 3 study groups: group 1, comprising children with infantile FPIAP (age $<6$ months, $\mathrm{n}=21 ; 11$ females and 10 males); group 2 , referring to FPIAP of older children (age $>1.5$ years, $n=7 ; 3$ females and 4 males), and group 3, including children with juvenile hyperplastic polyps ( $\mathrm{n}=22 ; 9$ females and 13 males). The mean age \pm SD of the patients in each group was as follows: group 1, $3 \pm 2$ months; group 2, $3.9 \pm 1.5$ years, 


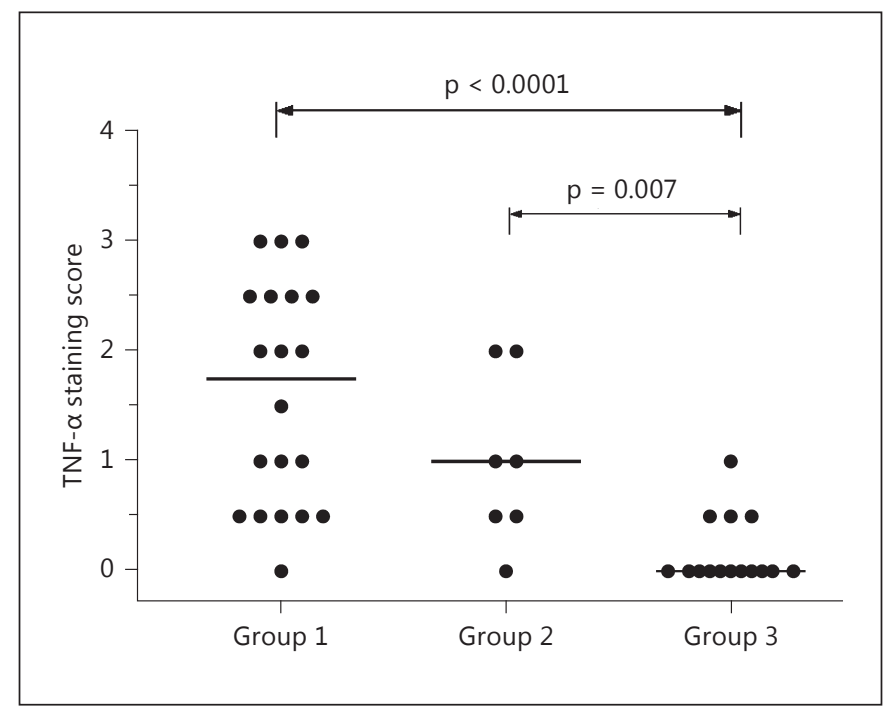

Fig. 1. The expression of TNF- $\alpha$ by lamina propria mononuclear cells was significantly higher in groups 1 and 2 compared to group 3.

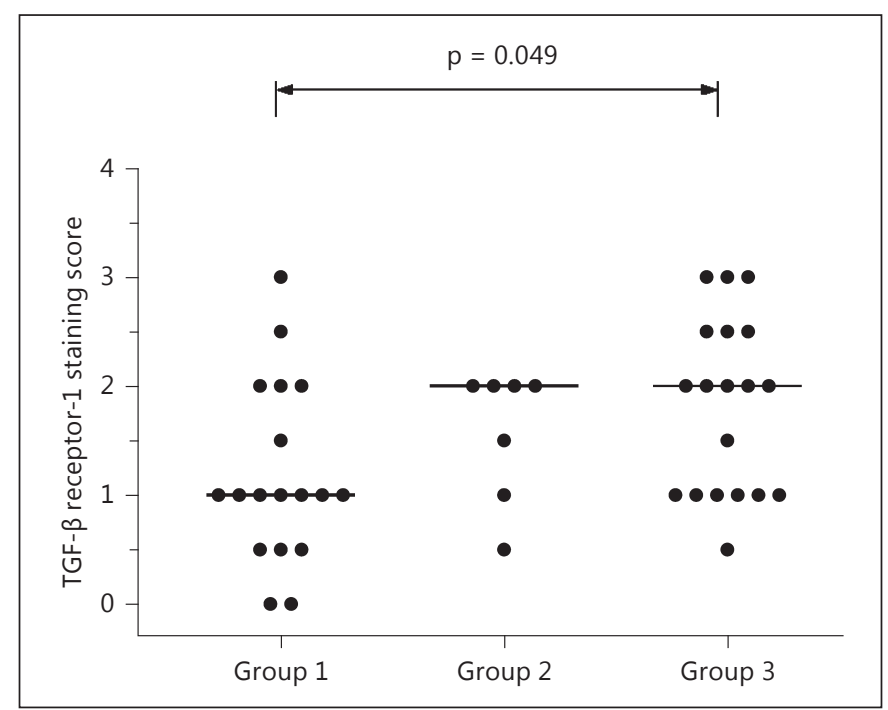

Fig. 3. The expression of TGF- $\beta$ receptor- 1 by lamina propria mononuclear cells was significantly lower in group 1 than group 3 .

and group 3, $5.4 \pm 4.7$ years. The median eosinophil counts/HPF and the interquartile range (IQR) values in the lamina propria of colon mucosa were as follows: group 1, 20 eosinophils/HPF (IQR 18-27.5), and group 2, 20 eosinophils/HPF (IQR 15-20).

In group 1, the median age at the onset of symptoms and the duration of symptoms before referral was 3 months ( 1 month in $25 \%$ of cases and 4 months in $75 \%$ of

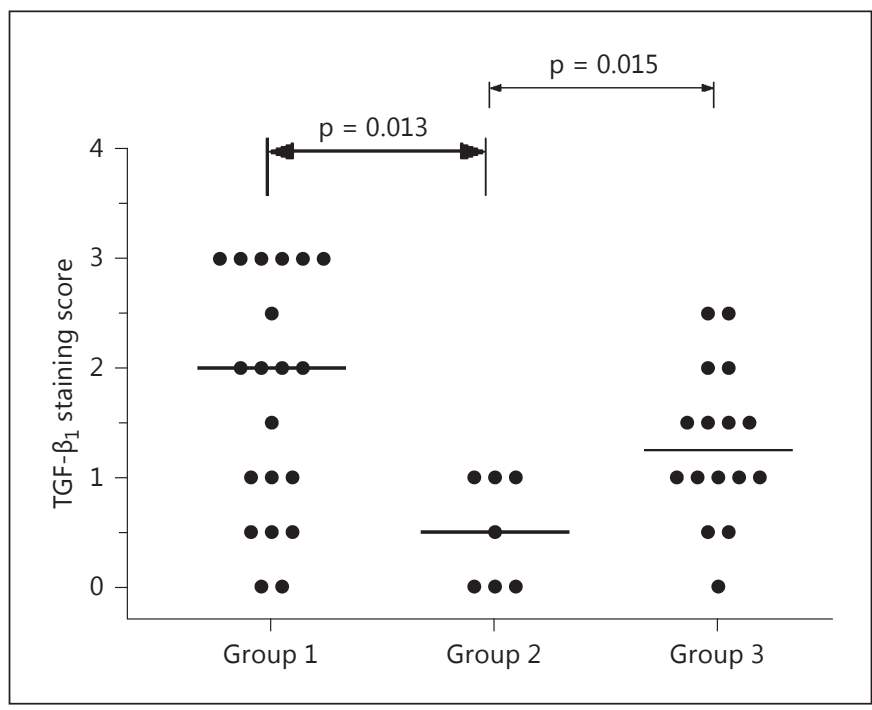

Fig. 2. The expression of TGF- $\beta_{1}$ by lamina propria mononuclear cells was significantly lower in group 2 compared to the other groups.

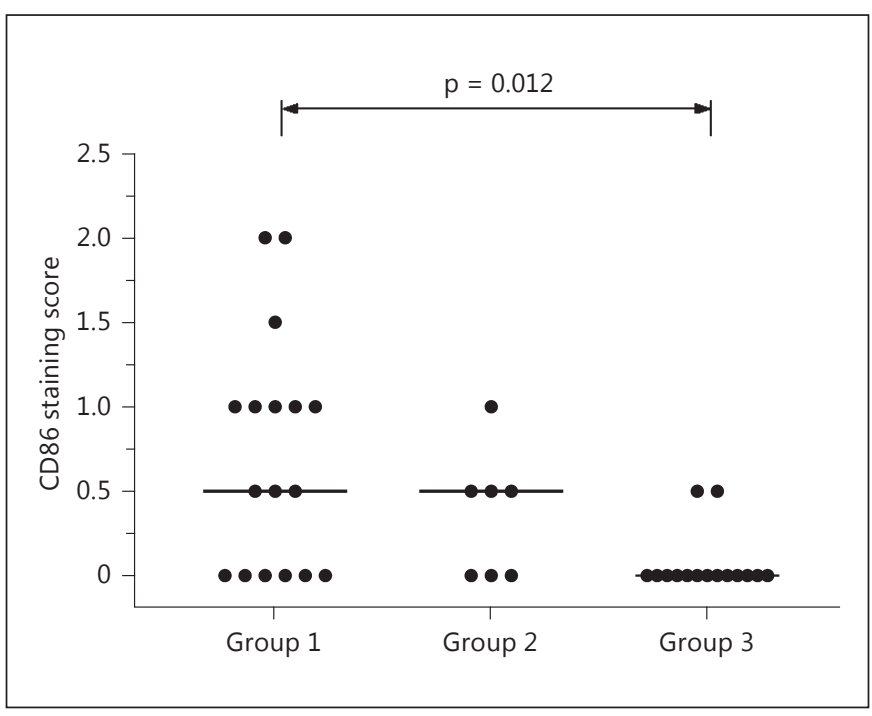

Fig. 4. The expression of CD86 by lamina propria mononuclear cells was significantly higher in group 1 compared to group 3 .

cases) and 9 days ( 4 days in $25 \%$ of cases and 14.5 days in $75 \%$ of cases), respectively. The presenting symptom was rectal bleeding (blood-streaked normal-to-soft stools) in all patients, with accompanying diarrhea with mucus in 7 patients. Seventeen patients were exclusively breast-fed, whereas 2 patients were fed a cow's milk-based formula and the remaining 2 had been receiving complementary feeding (solid foods and liquids other than breast milk).
64

Int Arch Allergy Immunol 2015;168:61-68 DOI: $10.1159 / 000441471$
Ozen/Gulcan/Ercan Saricoban/Ozkan/ Cengizlier 
Fig. 5. Expression of TGF- $\beta$ (a), TNF- $\alpha$ (c), and CD86 (e) on colon mucosa. Negative staining for TGF- $\beta$ (b), TNF- $\alpha$ (d), and CD86 (f).

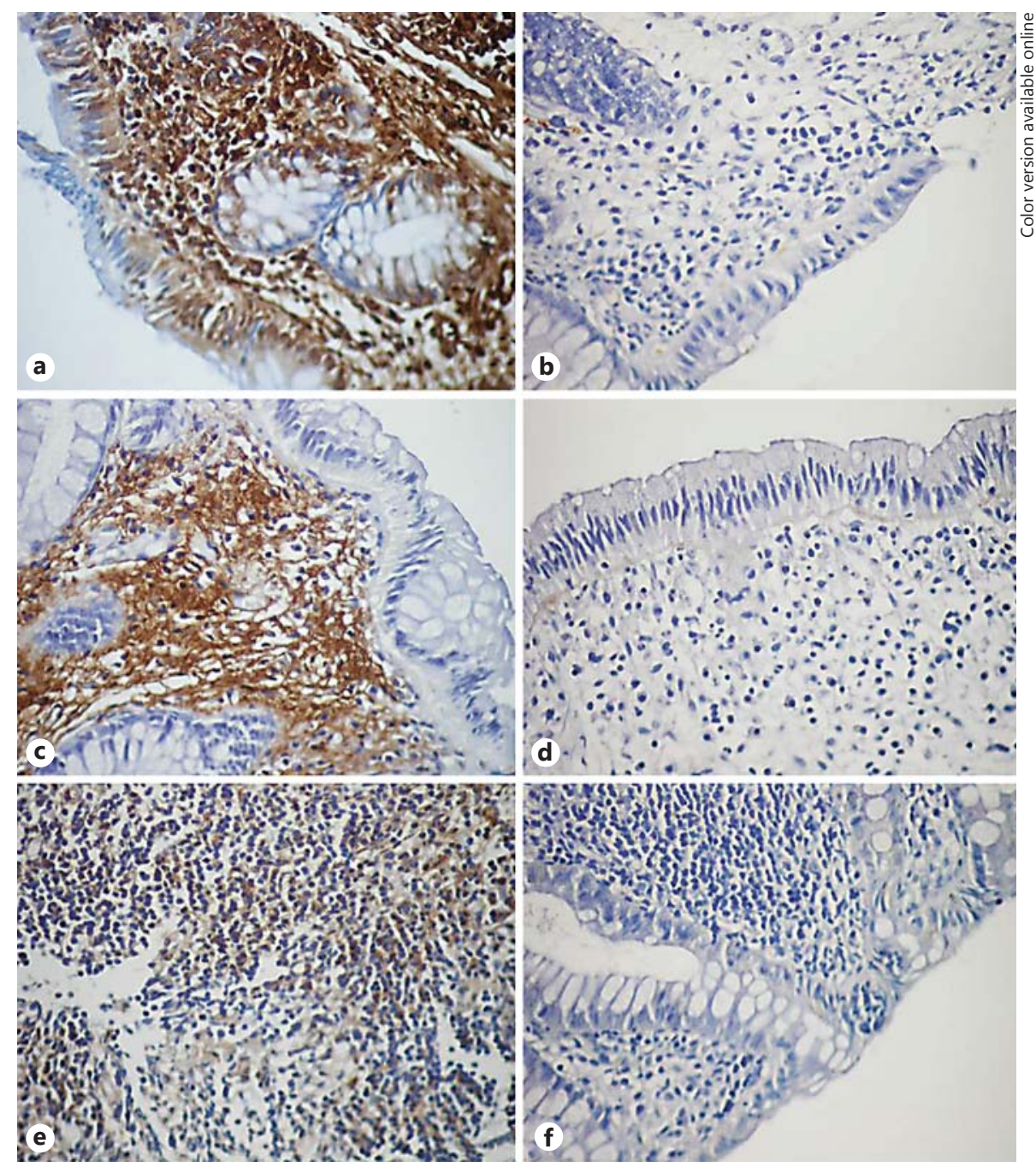

We examined the colonic mucosa in all infants, which revealed lymphonodular hyperplasia in 18 patients, focal erosion in 7 , and erythema in 3.

The staining score of TNF- $\alpha$ was significantly different between the 3 groups (table 1; fig. 1), i.e. it was higher in groups 1 and 2 compared to group 3 . The expression of TGF- $\beta_{1}$ was significantly lower in group 2 compared to the other groups (fig. 2). Group 1 patients had significantly lower TGF- $\beta$ receptor- 1 and higher CD86 staining scores compared to those in group 3 (fig. 3,4 ). However, the difference in the expression of TGF- $\beta$ receptor-1 should be treated cautiously since there was a remarkable overlap between the groups. The mean number of eosinophil counts/HPF in the lamina propria was slightly correlated with CD86 staining scores $(\mathrm{p}=0.026, \mathrm{r}=0.388)$. Figure 5 shows immunohistochemistry of colon biopsies for TNF- $\alpha$, TGF- $\beta_{1}$, and CD86.

Allergic Colitis Cytokines

\section{Discussion}

We found that the expression of TNF- $\alpha$ by mononuclear cells in the lamina propria of FPIAP of infancy and older children was higher than in juvenile polyps. A lower expression of TGF- $\beta_{1}$ in FPIAP of older children and a lower TGF- $\beta$ receptor-1 expression accompanied by higher CD86 staining scores in FPIAP of infancy were the most prominent findings.

FPIAP, also known as allergic proctocolitis or eosinophilic proctitis, has been classified under a group of disorders called primary EGID, which are defined as disorders that selectively affect the gastrointestinal tract, with eosinophil-rich inflammation in the absence of known causes of eosinophilia [22]. FPIAP has long been known to be a common cause of rectal bleeding in small infants. Recently, however, a series of 16 children between 2 and

Int Arch Allergy Immunol 2015;168:61-68 
14 years of age was described, with features remarkably similar to those observed in infancy FPIAP, providing evidence that FPIAP also affects older children [7]. In the current study, 7 patients (group 2) with these features were included. These patients were initially prescribed an oligoantigenic diet devoid of cow's milk. Overall, a satisfactory response was obtained with this exclusion diet, which, after a period of clinical remission, was followed by recurrence of rectal bleeding after an open challenge. Like the infantile form of FPIAP, these patients presented with rectal bleeding as the major and often only clinical manifestation. Apart from primary eosinophilic gastrointestinal diseases, eosinophil accumulation in the colon is a common feature of a variety of conditions, including inflammatory bowel disease, enteric infections, parasitic manifestations, drug reactions, and vasculitis [23-26].

FPIAP is usually a non-IgE associated disease in which a T-lymphocyte-mediated process has been suggested [27]. In this context, a fundamental principle underlying the development of an immunologic reaction to food antigens is the concept of oral tolerance. Most children with cow's milk allergy outgrow their symptoms over time, with the development of oral tolerance [28]. Given the bimodal age distribution and the fact that it is a non-IgEmediated condition unlike most other food allergies, the nature of the defects in tolerance might be quite different in FPIAP, even in its individual forms, i.e. those of infancy and older children. Whereas minute amounts of cow's milk proteins in breast-milk might cause sensitization and provoke symptoms at a much younger age in the former group, the latter group clinically becomes reactive to the offending food following a period of clinical unresponsiveness [29].

Food protein-induced enterocolitis syndrome (FPIES) is a non-IgE-mediated food allergy with mostly an acute presentation [30]. In a group of young infants with FPIES, the TGF- $\beta_{1}$ expression in the duodenal mucosa was found to be generally depressed or was not detected at all, both in patients and in control subjects, and this was attributed to the young age of the children [18]. It was demonstrated that the level of TGF- $\beta$ in the intestine and breast milk is subject to change with increasing age $[27,31]$. In breast milk, TGF- $\beta$ was highest in colostrum and decreased toward weaning, whereas the level of endogenous TGF- $\beta$ in the intestine increased significantly after mid-weaning. In our study, the expression of TGF- $\beta$ in the colon was not depressed in infantile FPIAP patients despite their young age. A likely explanation for this discrepancy might be the differences in the organization of the components of lymphoid tissue in the colon and small intestine.
In FPIAP of older children, the most prominent abnormality was the depressed expression of TGF- $\beta_{1}$. A previous study on toddlers with multiple food allergies clearly demonstrated by flow cytometry, immunohistochemistry, and in situ hybridization that the expression of TGF- $\beta_{1}$ was significantly decreased in the duodenal mucosa of children with either immediate or delayed adverse food reactions [17]. Our results support the previous suggestion that a reduced expression of TGF- $\beta_{1}$ might be implicated in the sensitization of children to dietary proteins because of an impaired TGF- $\beta$-mediated lowdose oral tolerance $[17,32,33]$.

TNF- $\alpha$ is a widely distributed cytokine involved in chronic inflammatory diseases. It has been shown to decrease the barrier capacity of intestinal cell lines by altering the tight junctions between epithelial cells [34, 35]. Previous studies on infants with FPIES have demonstrated elevated levels of TNF- $\alpha$ in peripheral blood lymphocytes and in duodenal biopsies [18, 35, 36]. Similar to FPIAP, FPIES is also a non-IgE-mediated food allergy disorder. These patients are mostly infants typically presenting with profuse vomiting after a symptom-free period of 2-6 h following ingestion of the offending food [37]. Colonic biopsies in these subjects may reveal diffuse cell inflammation with plasma cells and crypt abscesses [38]. Indeed, in enterocolitis the maximal inflammatory response is usually in the rectum. It has been suggested that the limitation of the inflammatory response to the lower colon in FPIAP may reflect a subset of infants with very mild enterocolitis [39].

It has also been demonstrated that fecal TNF- $\alpha$ levels are increased in children with atopic eczema and cow's milk allergy manifested by intestinal symptoms $[38,40]$. In our study, the expression of TNF- $\alpha$ was significantly higher in both groups of FPIAP compared to the patients with polyps. This finding suggests that TNF- $\alpha$ may be implicated in the pathogenesis of eosinophilic colitis in infants and children with FPIAP, possibly by altering the intestinal barrier capacity. In line with our observations, a recent study examining $\mathrm{T}$ cell responses to milk protein, TNF- $\alpha$ concentrations in the culture supernatants of milk protein-stimulated peripheral blood mononuclear cells from patients with gastrointestinal food allergies were significantly greater than those seen in patients with IgEmediated cow's milk allergy or control subjects [41].

The interaction between CD28 on T cells and its 2 ligands B7-1 (CD80) and B7-2 (CD86) on antigen presenting cells is considered the master costimulatory pathway for optimal T cell responses [42]. Previous studies have established the role of CD86 (B7-2) costimulation in the 
development of IgE responses in mouse models of allergic airway inflammation and hypersensitivity to peanut, whereas CD80 plays a role in the induction of low-dose tolerance to peanut $[43,44]$. We found that the expression of CD86 was higher in infants with FPIAP compared to controls. The differential role of various costimulatory molecules and subsets of dendritic cells in the induction of oral tolerance versus allergic sensitization in humans is a subject of further research.

A potential limitation of our study is the lack of agematched healthy controls. Since it would be unethical to perform endoscopies and biopsies in healthy infants, we included juvenile polyp samples to serve as controls. Further studies to compare FPIAP with other inflammatory disorders of the gastrointestinal system could provide a better understanding of the differential pathogenetic mechanisms involved. An exacerbated immune response to an internalized antigen among animals with active colitis was recently described [45]. Although the semiquantitative nature of the scoring of immunohistochemical stains might pose some limitations for an exact as- sessment of the tissue expression of these markers, the results of our study are still helpful in understanding the pathogenesis of FPIAP.

In conclusion, TNF- $\alpha$ might be implicated in the pathogenesis of FPIAP of infancy and childhood. The two subtypes of FPIAP appear to involve separate mechanisms: higher CD86 levels in the infantile form and a lower expression of TGF- $\beta$ in FPIAP of older children. Whether this heterogeneity accounts for two distinct pathways leading to a defect in mucosal tolerance or a primary failure to establish low-dose tolerance in the infantile form or loss of tolerance after it has been established in FPIAP of older children requires further investigation.

\section{Acknowledgements}

We express our appreciation to Ebru Şahin, Ebru Toka, Ferah Mutlu, and Zeliha Kilıç for their contributions to this study. This work was supported by The Yeditepe University Scientific Research Committee.

\section{References}

1 Machida HM, Catto Smith AG, Gall DG, Trevenen C, Scott RB: Allergic colitis in infancy: clinical and pathologic aspects. J Pediatr Gastroenterol Nutr 1994;19:22-26.

2 Chang JW, Wu TC, Wang KS, Huang IF, Huang B, Yu IT: Colon mucosal pathology in infants under three months of age with diarrhea disorders. J Pediatr Gastroenterol Nutr 2002;35:387-390.

3 Goldman H, Proujansky R: Allergic proctitis and gastroenteritis in children; clinical and mucosal biopsy features in 53 cases. Am J Surg Pathol 1986;10:75-86.

4 Odze RD, Bines J, Leichtner AM, Goldman H, Antonioli DA: Allergic proctocolitis in infants: a prospective clinicopathologic biopsy study. Hum Pathol 1993;24:668-674.

5 Rothenberg ME: Eosinophilic gastrointestinal disorders (EGID). J Allergy Clin Immunol 2004;113:11-28, quiz 29.

6 Ohtsuka Y, Jimbo K, Inage E, Mori M, Yamakawa Y, Aoyagi Y, Suzuki M, Kudo T, Suzuki R, Shimizu T: Microarray analysis of mucosal biopsy specimens in neonates with rectal bleeding: is it really an allergic disease? J Allergy Clin Immunol 2012;129:1676-1678.

7 Ravelli A, Villanacci V, Chiappa S, Bolognini S, Manenti S, Fuoti M: Dietary protein-induced proctocolitis in childhood. Am J Gastroenterol 2008;103:2605-2612.

8 Lake AM, Whitington PF, Hamilton SR: Dietary protein-induced colitis in breast-fed infants. J Pediatr 1982;101:906-910.
9 Jenkins HR, Pincott JR, Soothill JF, Milla PJ, Harries JT: Food allergy: the major cause of infantile colitis. Arch Dis Child 1984;59:326329.

10 Sampson HA: Food allergy. J Allergy Clin Immunol 2003;111:S540-S547.

11 Järvinen KM: Allergy prevention via co-administration of intact food allergen and its epitope soup? Int Arch Allergy Immunol 2013;161:195-196.

12 Katz Y, Rajuan N, Goldberg MR, Eisenberg E, Heyman E, Cohen A, Leshno M: Early exposure to cow's milk protein is protective against IgE-mediated cow's milk protein allergy. J Allergy Clin Immunol 2010;126:77-82.

13 Schoemaker AA, Sprikkelman AB, Grimshaw KE, Roberts G, Grabenhenrich L, Rosenfeld L, Siegert S, Dubakiene R, Rudzeviciene O, Reche M, Fiandor A, Papadopoulos NG, Malamitsi-Puchner A, Fiocchi A, Dahdah L, Sigurdardottir ST, Clausen M, StańczykPrzyłuska A, Zeman K, Mills EN, McBride D, Keil T, Beyer K: Incidence and natural history of challenge-proven cow's milk allergy in European children - EuroPrevall birth cohort. Allergy 2015;70:963-972.

14 Chehade M, Mayer L: Oral tolerance and its relation to food hypersensitivities. J Allergy Clin Immunol 2005;115:3-12, quiz 13.

15 Perez-Machado MA, Ashwood P, Thomson MA, Latcham F, Sim R, Walker-Smith JA, Murch SH: Reduced transforming growth factor-beta1-producing $\mathrm{T}$ cells in the duode- nal mucosa of children with food allergy. Eur J Immunol 2003;33:2307-2315.

16 Chung HL, Hwang JB, Park JJ, Kim SG: Expression of transforming growth factor betal, transforming growth factor type I and II receptors, and TNF-alpha in the mucosa of the small intestine in infants with food proteininduced enterocolitis syndrome. J Allergy Clin Immunol 2002;109:150-154.

17 van Wijk F, Nierkens S, de Jong W, Wehrens EJ, Boon L, van Kooten P, Knippels LM, Pieters $\mathrm{R}$ : The CD28/CTLA-4-B7 signaling pathway is involved in both allergic sensitization and tolerance induction to orally administered peanut proteins. J Immunol 2007;178:6894-6900.

18 Yu LC, Yang PC, Berin MC, Di Leo V, Conrad DH, McKay DM, Satoskar AR, Perdue MH: Enhanced transepithelial antigen transport in intestine of allergic mice is mediated by IgE/ CD23 and regulated by interleukin-4. Gastroenterology 2001;121:370-381.

19 Hwang JB, Park MH, Kang YN, Kim SP, Suh SI Kam S: Advanced criteria for clinicopathological diagnosis of food protein-induced proctocolitis. J Korean Med Sci 2007;22:213-217.

20 Kumar D, Repucci A, Wyatt-Ashmead J, Chelimsky G: Allergic colitis presenting in the first day of life: report of three cases. J Pediatr Gastroenterol Nutr 2000;31:195-197.

21 Kumagai H, Masuda T, Maisawa S, Chida S: Apoptotic epithelial cells in biopsy specimens from infants with streaked rectal bleeding. J Pediatr Gastroenterol Nutr 2001;32:428-433. 
22 Rothenberg ME: Eosinophilic gastrointestinal disorders (EGID). J Allergy Clin Immunol 2004;113:11-28, quiz 29.

23 Sarin SK, Malhotra V, Sen Gupta S, Karol A, Gaur SK, Anand BS: Significance of eosinophil and mast cell counts in rectal mucosa in ulcerative colitis: a prospective controlled study. Dig Dis Sci 1987;32:363-367.

24 Dvorak AM: Ultrastructural evidence for release of major basic protein-containing crystalline cores of eosinophil granules in vivo: cytotoxic potential in Crohn's disease. J Immunol 1980;125:460-462.

25 Penttila IA, van Spriel AB, Zhang MF, et al: Transforming growth factor-beta levels in maternal milk and expression in postnatal rat duodenum and ileum. Pediatr Res 1998;44: 524-531.

26 Yamada Y, Nishi A, Kato M, Toki F, Yamamoto H, Suzuki N, Hirato J, Hayashi Y: Esophagitis with eosinophil infiltration associated with congenital esophageal atresia and stenosis. Int Arch Allergy Immunol 2013; 161(suppl 2):159-163.

27 Van Sickle GJ, Powell GK, McDonald PJ, Goldblum RM: Milk- and soy protein-induced enterocolitis: evidence for lymphocyte sensitization to specific food proteins. Gastroenterology 1985;88:1915-1921.

28 Miceli Sopo S, Arena R, Greco M, Bergamini $\mathrm{M}$, Monaco S: Constipation and cow's milk allergy: a review of the literature. Int Arch Allergy Immunol 2014;164:40-45.

29 Miceli Sopo S, Monaco S, Greco M, Scala G: Chronic food protein-induced enterocolitis syndrome caused by cow's milk proteins passed through breast milk. Int Arch Allergy Immunol 2014;164:207-209.
30 Miceli Sopo S, Battista A, Greco M, Monaco $S$ : Ondansetron for food protein-induced enterocolitis syndrome. Int Arch Allergy Immunol 2014;164:137-139.

31 Saito S, Yoshida M, Ichijo M, Ishizaka S, Tsujii T: Transforming growth factor- $\beta$ in human milk. Clin Exp Immunol 1993;94:220-224.

32 Beyer K, Castro R, Birnbaum A, Benkov K, Pittman N, Sampson HA: Human milk-specific mucosal lymphocytes of the gastrointestinal tract display a TH2 cytokine profile. J Allergy Clin Immunol 2002;109:707-713.

33 Murch S: Diabetes and cows' milk. Lancet 1996;348:1656.

34 Heyman M, Darmon N, Dupont C, et al: Mononuclear cells from infants allergic to cow's milk secrete tumor necrosis factor alpha, altering intestinal function. Gastroenterology 1994;106:1514-1523.

35 Rodriguez P, Heyman M, Candalh C, Blaton MA, Bouchaud C: Tumour necrosis factoralpha induces morphological and functional alterations of intestinal HT29 cl.19A cell monolayers. Cytokine 1995; 7:441-448.

36 Benlounes N, Candalh C, Matarazzo P, Dupont C, Heyman M: The time-course of milk antigen-induced TNF-alpha secretion differs according to the clinical symptoms in children with cow's milk allergy. J Allergy Clin Immunol 1999;104:863-869.

37 Eigenmann PA: Mechanisms of food allergy. Pediatr Allergy Immunol 2009;20:5-11.

38 Majamaa $\mathrm{H}$, Miettinen A, Laine S, Isolauri E: Intestinal inflammation in children with atopic eczema: faecal eosinophil cationic protein and tumour necrosis factor-alpha as noninvasive indicators of food allergy. Clin Exp Allergy 1996;26:181-187.

39 Lake AM: Food-induced eosinophilic proctocolitis. J Pediatr Gastroenterol Nutr 2000; 30:S58-S60.
40 Kapel N, Matarazzo P, Haouchine D, Abiola N, Guerin S, Magne D, Gobert JG, Dupont C: Fecal tumor necrosis factor alpha, eosinophil cationic protein and IgE levels in infants with cow's milk allergy and gastrointestinal manifestations. Clin Chem Lab Med 1999;37:2932.

41 Morita H, Nomura I, Orihara K, Yoshida K, Akasawa A, Tachimoto H, Ohtsuka Y, Namai Y, Futamura M, Shoda T, Matsuda A, Kamemura N, Kido H, Takahashi T, Ohya Y, Saito H, Matsumoto K: Antigen-specific Tcell responses in patients with non-IgE-mediated gastrointestinal food allergy are predominantly skewed to $\mathrm{T}_{\mathrm{H}} 2$. J Allergy Clin Immunol 2013;131:590-592.

42 Harding FA, McArthur JG, Gross JA, Raulet $\mathrm{DH}$, Allison JP: CD28-mediated signalling co-stimulates murine T cells and prevents induction of anergy in T-cell clones. Nature 1992;356:607-609.

43 van Wijk F, Nierkens S, de Jong W, et al: The CD28/CTLA-4-B7 signaling pathway is involved in both allergic sensitization and tolerance induction to orally administered peanut proteins. J Immunol 2007; 178:6894-6900.

44 Keane-Myers AM, Gause WC, Finkelman FD, Xhou XD, Wills-Karp M: Development of murine allergic asthma is dependent upon B7-2 costimulation. J Immunol 1998; 160 : 1036-1043.

45 Cueto-Sola M, Bailon E, Utrilla P, RodríguezRuiz J, Garrido-Mesa N, Zarzuelo A, Xaus J, Gálvez J, Comalada M: Active colitis exacerbates immune response to internalized food antigens in mice. Int Arch Allergy Immunol 2013;162:214-224. 